\begin{tabular}{c} 
journal homepage: http://ijiemjournal.uns.ac.rs/ \\
International Journal of Industrial \\
Engineering and Management \\
volume $11 /$ No $2 /$ June $2020 / 104-115$ \\
\hline
\end{tabular}

Review article

\title{
The concept of 'talent' \\ in the labor management perspective \\ - the bibliometric analysis of literature
}

\author{
Y. Barkun, E. Rollnik-Sadowska, E. Glińska * \\ Bialystok University of Technology, Faculty of Engineering Management, Bialystok, Poland
}

\begin{abstract}
A B STRACT
The article aims to identify areas of the scientific research within which the subject matter of "talent" in the labour management perspective is addressed. The research prepositions are based on the bibliometric data analysis characterizing scientific publications indexed by the Scopus and Web of Science databases. To achieve the aim, VOSviewer software was implemented, what facilitated identification of the keywords, visualized correspondence between them. The results of the study illustrate the following key research trends: the analysis of demand for talents from the business and regional perspectives.
\end{abstract}

\section{ARTICLE INFO \\ Article history:}

Received January 31, 2020

Revised April 4, 2020

Accepted April 8, 2020

Published online May 6, 2020

Keywords:

Talent management;

Human resource management;

Bibliometrics;

Labour market

*Corresponding author:

Ewa Glinska

e.glinska@pb.edu.pl

\section{Introduction}

The academic literature represents a variety of articles examining the trends in human resource management. The global environment shapes the general patterns; however, they differ by countries' specificity on the macro-level and companies' distinction on the micro-level [1]. Though researchers approach the labour market from the perspective of different factors, they currently agree that the majority of economic entities demand employees with high qualifications. From the end of the 1990s, the term "war for talents" was introduced to the academic literature, and from then, it has been widely developed and discussed [2]. Painter-Morland et al. [3] noticed talent management inclined in "a corporate buzzword that has become a priority of boards of directors, human resource (HR) managers and recruitment agencies alike". It appears to be both a practical tool and a theoretical concept. Considering the mutual contribution of theory and practice, it is vital to analyze what the current trends and directions of analysis in the literature are.

Therefore, the aim of the article is to understand the current state of research on the subject of talent in the labour perspective and the evolution of publications, authors or countries in which these investigations are framed. The authors of the article searched for answers to the following research question: what are the main directions of research in the area of talent management with respect to the labour market 
perspective. In search for answers to this question, bibliometric analysis of scientific articles published in journals indexed in the Web of Science and Scopus databases was used. Bibliometric analysis is a useful tool, which facilitates the evaluation of developments in knowledge on a specific subject and assesses the scientific influence of research and sources [4].Special software, such as VOSviewer, propose a faster and easier way of data processing and assist visualization of the research results. Thus, this article represents how methodological approach with involvement of contemporary research tool facilitates the identification of the main trends in the field of talent and labour management and, from there, proposal future research initiatives.

The paper is organized as follows. Section one presents an introduction to the theme and a literature review on 'talent' concept. Section two contains a brief overview of the bibliometric method. Section three covers the presentation of results of bibliometric analysis. Finally, the last section includes some final remarks concerning the conducted bibliometric analysis.

\section{The concept of 'talent' in the scientific literature}

Progress and innovations increase the requirements towards employees' competencies. Nowadays, academics, as well as practitioners, recognize a specific group of highly-skilled individuals, that is called talents. Talents are unequally distributed geographically [5]. Creation of conditions for attracting talents requires efforts both from companies and governments, and those actions should be run as one mechanism.

Labour force is the center of the human capital theory. The importance of the human factor has been recognized since Adam Smith times [6]. The term "human capital" was first defined by Schultz [7] as human abilities in which knowledge and skills are embedded. However, the definition of human capital is actively discussed, because, first of all, some of them are not sure if the term "capital" is used properly, and secondly, if this category should be analyzed in the organizational or macro-level [8]. Previously, the concept stated that "people need companies", however, nowadays is the time of employee labour market or in other words, "companies need people" [9]. Different economic units are interested in the high quality of employees rather than in their quantity [10].
Human capital can be divided into general that is applicable for various occupations and industries, and specific which is relevant for a certain occupation or industry, and its application is limited [10]. The human capital value is changeable, and it depends on a person or the extent on which it generates value for the firm. Human capital is often evaluated through the following criteria: educational level, employment knowledge intensity, employee know-how; indicators suggested by the concept of the creative class, including indicators of talent and tolerance of the workforce; a correlation between human capital and innovativeness in the national context [12]. Human resource management has evolved from personnel management, and nowadays, talent management is its widely recognized part and refers to a broad cluster of policies and practices [13], [14].

International Labour Organization defines four skill levels depending on the complexity and range of tasks that are needed to be performed in an occupation, ranged from simple jobs to complex problem-solving [15]. Researchers besides the category "highly-skilled" employees distinguish the category "talents". The major dissimilarities that differ a "talent" from a "highly-qualified specialist" is that a "talent" is characterized by intelligence that can affect the job performance and that is complicated to achieve, and the complexity of a "talent's" tasks is "objectively" more cognitively demanding than others, even for experienced workers [16]. If to give a brief definition of talent, it consists of the combination of 'competence, commitment and contribution' [9].

Originally, talent management arose at the micro-level as a practical instrument for companies and later on, it has evolved into a theoretical concept. The term "war for talents" was implemented by Hudson Institute's in 1986 in a report predicting major skill shortages in the USA, and later the concept was developed by Steven Hankin in 1997 [17], [2]. "War for talents" refers to the increasingly fierce competition to attract and retain employees at a time when too few workers are available to replace the baby boomers now departing the workforce in advanced economies" [18]. According to Cooke et al. [19], currently exist four main streams in defining talent management: (1) as a newer fashion of human resource management, (2) as succession planning, (3) the management of talented employees, (4) the strategic management of "pivotal positions".

Within the research of Romer, it was figured out, that the category "human capital" can be applied not only to a company, but to the whole country, and there is a positive correlation between the amount of 
human capital and its GDP [8]. Governments of the number of countries, such as Australia, Canada, Germany, UK and USA take an active part in designing conditions for attracting talents to the regions and developing immigrant-friendly policies [1].

Talent management is defined as "systematically utilizing international human resource management activities to attract, develop, and retain individuals with high levels of human capital consistent with the strategic directions of the multinational enterprise in a dynamic, highly competitive, and global environment" [1]. The contemporary concept of talent management is human-centric, and the approaches for management that are offered by the researchers depend on whom they consider being "talents" [20].

One of the concerns appearing due to progress is connected with the mismatches between the skills that a worker has and real demands of the economy [21]. According to the human capital theory, migration can be positioned as an investment to improve probable real income streams in future and further employment opportunities [22]. The flow or migration of human capital, when it is connected with the high-skilled employees and talents, is often called brain gain for the receiving country and brain drain for the country of origin. Brain drain is used to refer to the mobility of the most highly skilled individuals in different regions, industries and occupations [23], 24]. One of the assumptions of the talent management studies is that brain drain as an inevitable part of globalization makes rich economies richer and poor economies poorer [25].

In order to elaborate a strategy for attracting human capital, it is essential to know what the reasons for migration are. Some researchers conclude that the key exogenous drivers influencing the talent flows belong to the following categories: globalization, demographics, and the demand-supply gap [26]. Economic development is an essential criterium for attracting talents. However, intangible criteria are important as well [27]. In the literature, the following classification is frequently mentioned: demand-pull factors in the destination area, supply-push factors in the origin area, and network factors that link origin and destination [28]. According to the contemporary theories of the human capital migration, individuals make a decision to move basing on the estimated outcomes they expect to get from changing their place [29], [30]. The following factors shape the quantity and quality of talents in the economy: (1) demographic and economic trends; (2) increasing mobility of people and organizations; (3) transformational changes to business environments, skills and cultures; and (4) growing levels of workforce diversity [1].

Human capital is a complex system for management, and the complexity is connected with the intelligence of the human, that means in order to make this capital work, it is not enough to create certain external conditions, but also some motivation is needed. The actions undertaken to manage the talent flow can be divided into two groups: attracting talents, and designing immigration and integration policies identifying the most desirable immigrants and encouraging them to stay [31].

\section{Research methods}

To achieve the aim of the paper, a systematic review of scientific literature containing the references to the phrases "talent" and "labour" and at the same time indexed by the Scopus and Web of Science (WoS) databases till 2018, was conducted. They are the most popular bibliographic and abstract databases, which are characterized by high quality of accumulated resources [32].

The bibliometric analysis method was selected because it allows to estimate the impact of publications, demonstrates the level of elaboration of the topic in the literature and facilitates the recognition of the latest trends [4]. Two principal procedures were applied: performance analysis and science mapping [33].

The review consisted of the three stages. In the first stage of the research, two lists of articles were generated, which in its bibliographic description contain references to two phrases: "talent" and "labour". The generated lists included: 727 records from Scopus and 922 records from $\mathrm{WoS}_{\mathrm{O}}$ database.

On the second stage of the research, a bibliometric analysis separately for each of the lists was made. It included: identification the number of articles dealing with the analyzed topics taking into account the year of their publication, numbers of citations per year (including self-citations), identification of papers authors' by country, as well as subject area of papers in which the authors of the articles conducted research.

On the last stage of research, the results were processed and presented with the support of VOSviewer software which allowed to prepare a map showing the existing relationships between keywords indicated by authors of articles.

The VOSviewer software is particularly useful for working with a sheer volume of data [34]. It is a tool for constructing and visualising bibliometric networks, which use an advanced clus- 
tering techniques to show the relationships between keywords characterising articles from scientific databases. The program highlights the frequency and co-occurrence of keywords that appear in the network [35], [36].

The VOSviewer software facilitated the combination of the set of data into clusters [37]. A cluster is a set of closely related nodes. Each node in a network is assigned to exactly one cluster. The number of clusters is determined by a resolution parameter [38]. Cluster analysis allowed to identify the main areas of research in the area of "talent" and "labour". As for the analysis parameter, the minimum number of occurrences equal to 5 was determined. As a result, the number of keywords to be selected was 50 in Scopus database and 38 in WoS database. The bibliometric network allows for identification of six clusters including the below keywords in both databases.

\section{The result of the bibliometric analysis of the topic "talent" in the labour perspective}

Although the "talent" concept became popular with researchers at the beginning of the 2000s, the first journal that refers to the "talent" in the context of labour topic was published in 1933 by Oxford University Press, in the Musical Quarterly.

Generally, the concept of 'talent' in the labour perspective is not significantly widespread in the scientific literature. However, a gradual growth of the number of publications appearing in the selected databases within the last fifteen years can be observed figure 1 . This indicates a growing interest of scientists in the analyzed subject.

The upward trend in citations of the publications relating to the "talent" concept in the labour perspective also confirms growing interest in that subject figure 2 .

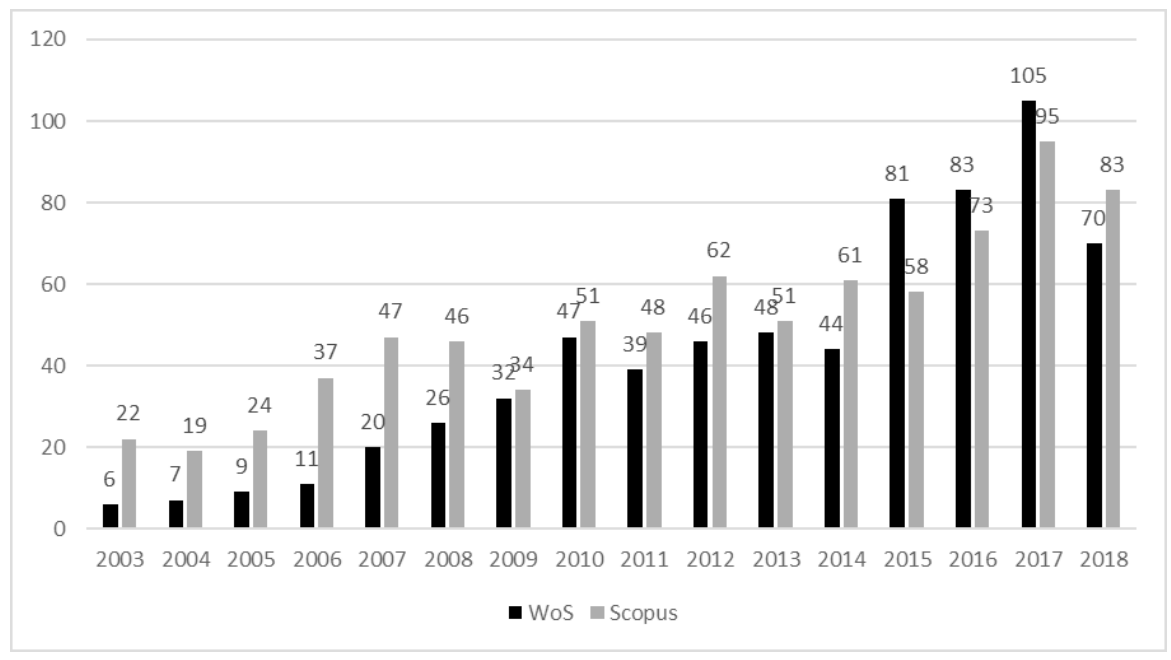

Figure 1. Number of publications per year

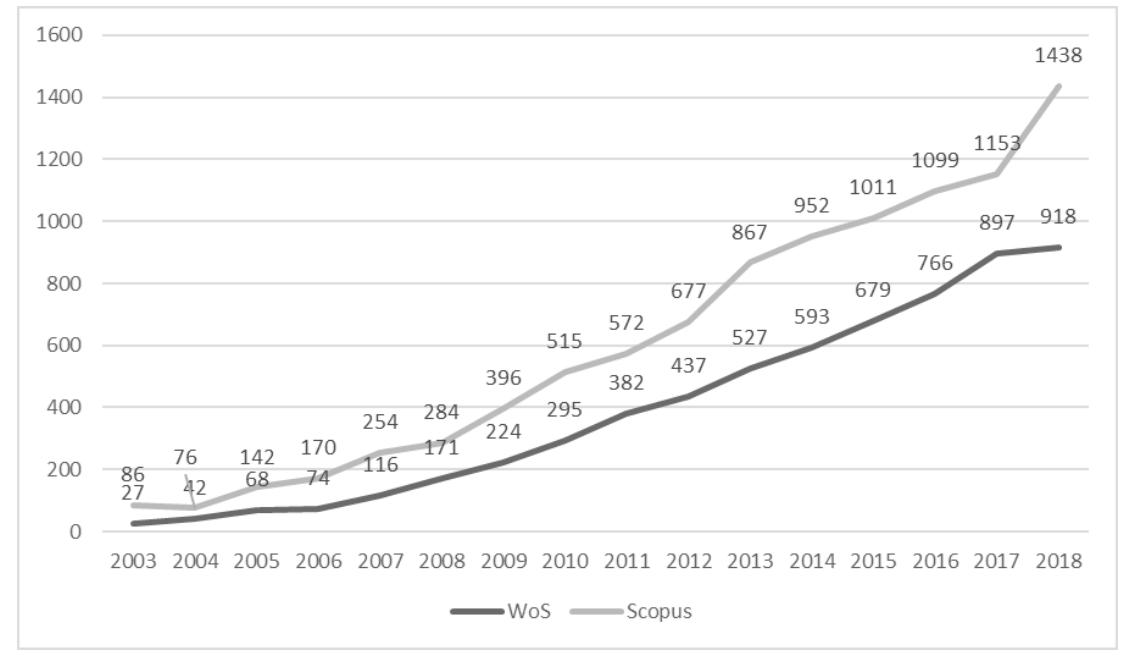

Figure 2. Number of citation (including self-citation) 
The ranking of the most influential countries (figures $3-4$ ) is headed by the USA, with about a third of the total contributions - 27\% (WoS), 31\% (Scopus). This is followed by China with 140 and 73 articles on WoS and Scopus, respectively and the United Kingdom - 82 articles on WoS and 105 on Scopus.

The analysis of the most popular subject area for the concept of "talent" in the labour perspective indicates that the majority of publication were located

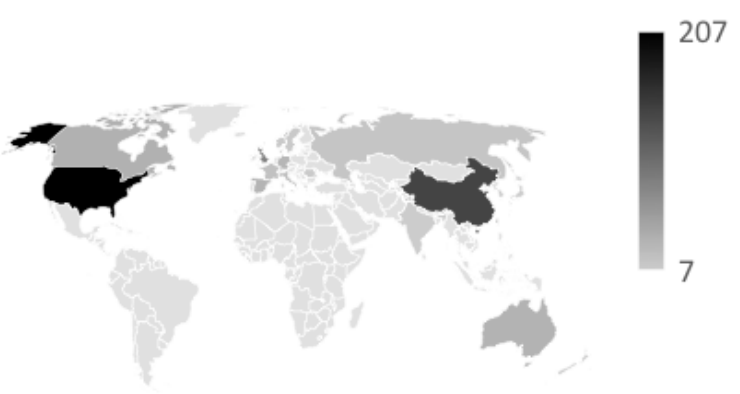

Figure 3. Documents by country (1992-2019) - WoS

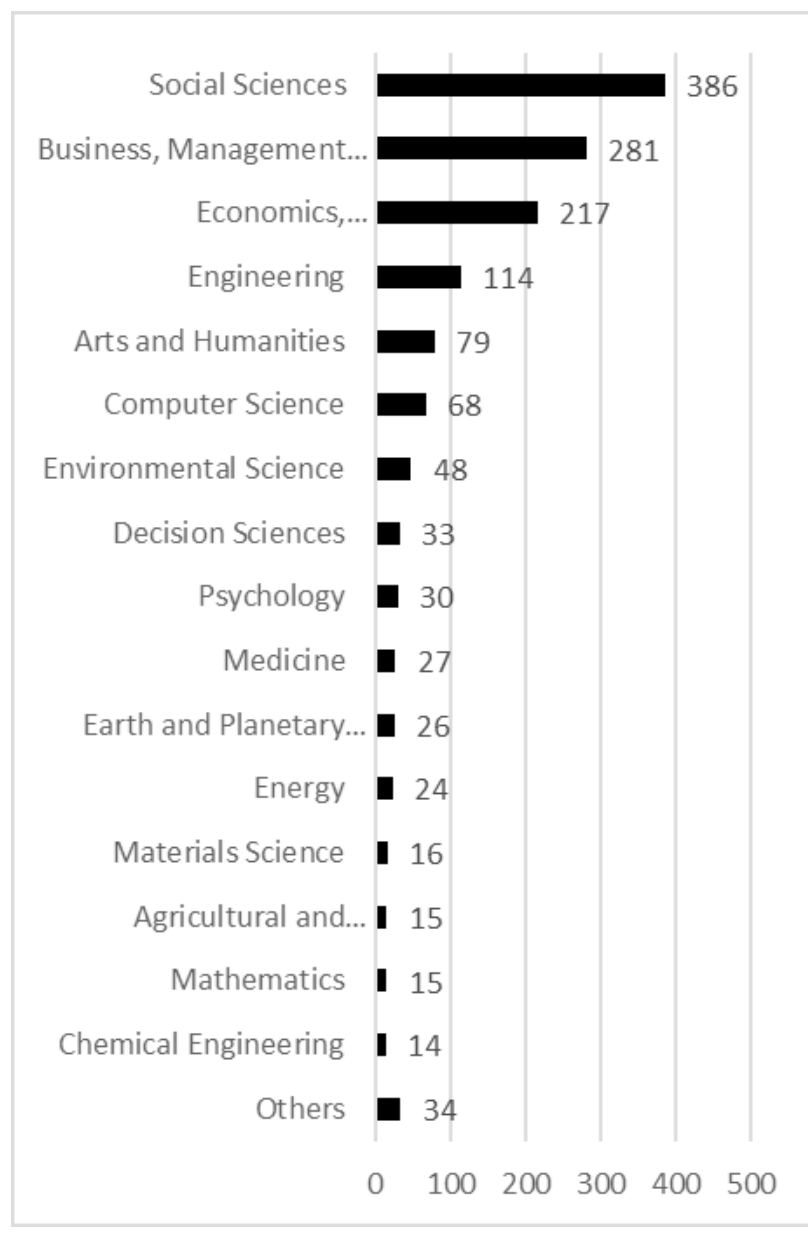

Figure 5. Documents by subject area (1933-2019) - Scopus in social sciences - economics, business and management (figures 5 - 6).

In order to analyze the occurrence of the most frequent terms used by the authors in their research on "talent" in the labour perspective, a trend map was created, using a fractional counting method and based on the bibliographic data on co-occurrence of the keywords used by the authors in the Scopus and WoS databases (figures 7 - 8).

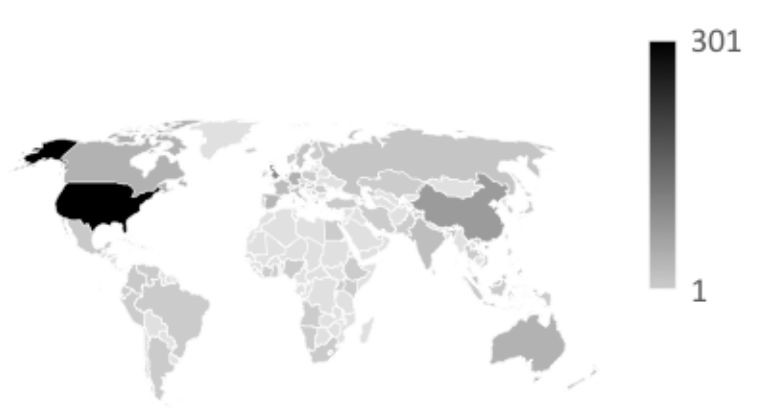

Figure 4. Documents by country (1933-2019) - Scopus

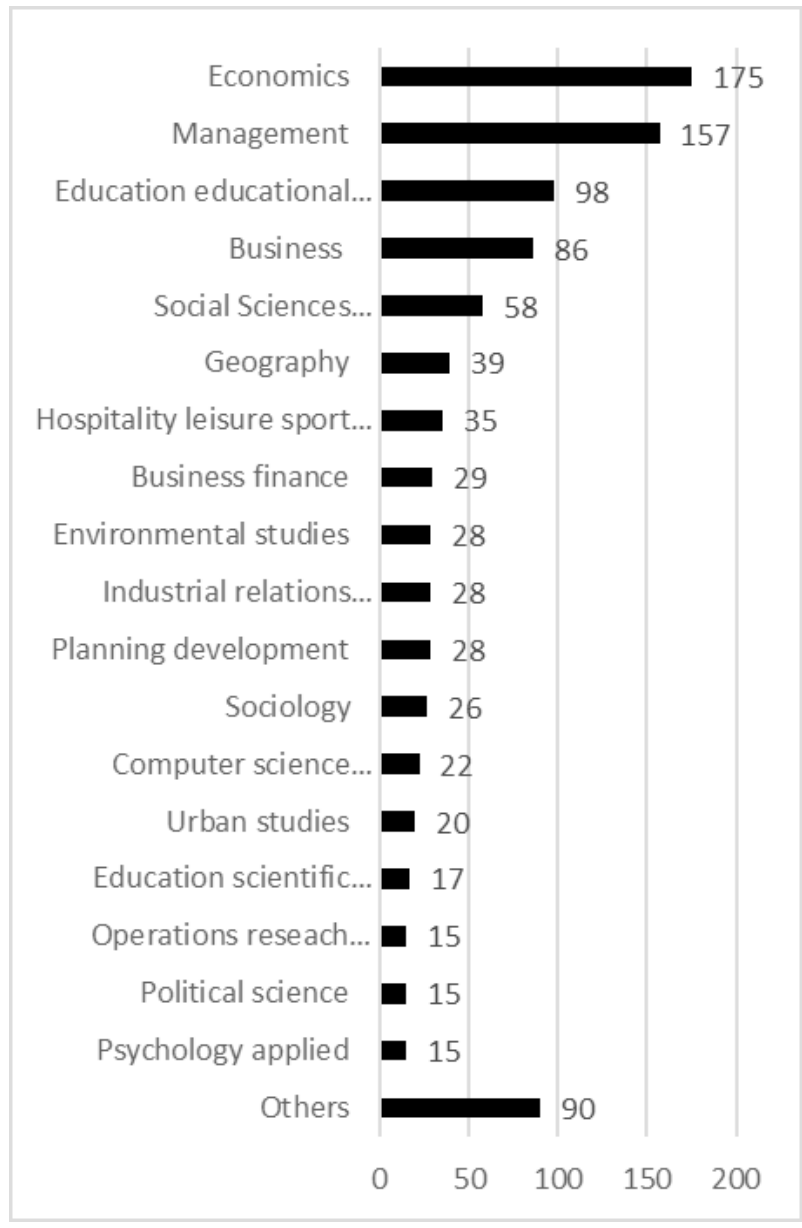

Figure 6. Documents by subject area (1992-2019) - WoS 


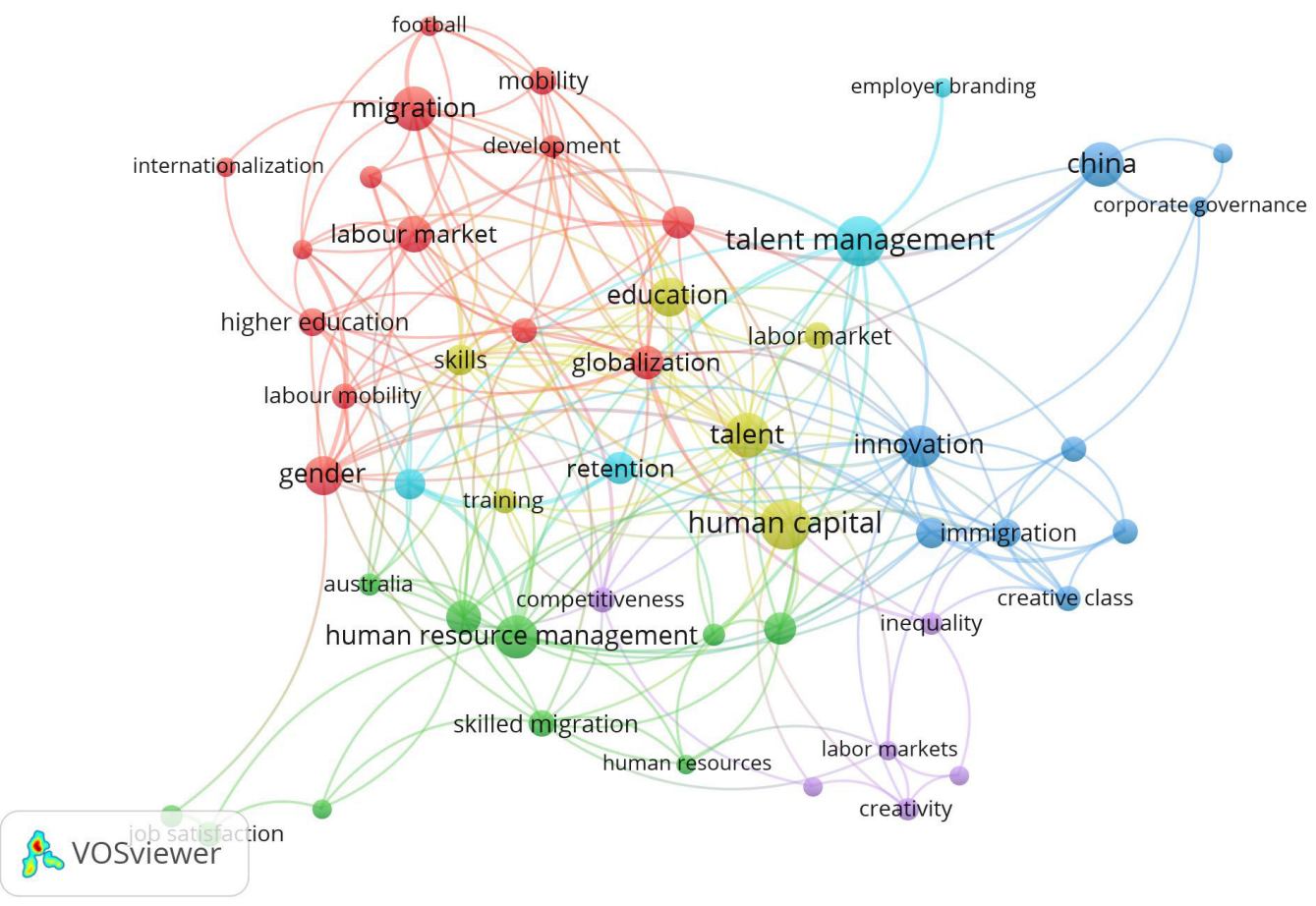

Figure 7. Map of research trends (Scopus)

The first cluster in the Scopus database included thirteen keywords: brain drain, Canada, development, gender, globalization, higher education, highly skilled migrants, internationalization, labour market, labour mobility, migration, mobility, students. In this cluster we can find articles dealing with the subject of migration of young people for purposes related to education as well as professional work. The articles in this group also deal with the subject of brain drain, which is the effect of the mobility of highly qualified people. The background of the considerations undertaken by the authors of the articles from the first cluster is globalization and the internationalization of the career of young employees connected with it. Globalization increases the mobility of highly-skilled human capital [39]. Canada, as a country facing an excessive brain gain, faces the problem of "brain waste" when there are too many barriers and requirements are established for the foreign candidates, specifically Chinese [40].

In the second cluster there were eleven keywords: creative class, diversity, economic development, education, entrepreneurship, human capital, immigration, innovation, labor market, management, talent. This cluster mainly focuses on diversified, educated human capital including creative class and immigrant resources as drivers of economic development, entrepreneurship and innovation. Those relations take place in the labour market in terms of talent manage- ment. According to Qian [41], there are two types of talent distinguished in literature: human capital (measured by the education attainment) and creative class (occupational skill). In order to maximize the benefits of integrating those employees in company's resources, those two types require management approaches varying to some extent from each other.

Cluster number three consisted of ten keywords: Australia, career development, employment, human resource management, human resources, India, job satisfaction, knowledge economy, motivation, skilled migration. In the third cluster, the issue of operating in the knowledge economy is covered. Changes in the economic environment shape different labour market that require adaptation of human resource management techniques. Increased mobility of human resources boosts the outflow of employees from less developed countries to more developed. Therefore, the latest in order to sustain economic development elaborate and modify tools to motivate skilled migrants to seek employment in their countries. Australia as a popular destination for migration frequently appears as the object of analysis, as well as India as one of the world's donors of employees. Job satisfaction, motivation and career development are among the key factors to investigate the decision-making process among talented migrants.

In cluster four could be found six keywords: competitiveness, creativity, inequality, labor markets, oc- 
cupational choice, productivity. The main keywords as competitiveness and creativity are understood in economic terms, which create a new field for inequality on the labour markets. Inequality in the talent management literature is often analyzed in the two main forms: inequal regional distribution of talents [42] and diversity of skills of human that influence inequality in society. Creativity is a crucial competency required from the talents in the economic sectors of different complexity [43]. The approaches of competitiveness and creativity improve occupational choice and labour productivity.

Cluster number five included five keywords: China, corporate governance, employer branding, executive compensation, talent management. This cluster includes articles dealing with the subject of relations between corporate governance and employer branding and talent management in organizations. Employer branding is a new dimension in managing the talent of an organization from the perspective of retention and attraction management. This concept has become a top priority for organizations in their quest to win the war for talent [44]. Nowadays companies aim to incorporate specific activities to create an attractive and motivating organizational environment in order to improve employer brand to attract and retain talents [45].

In the last cluster there were four keywords: recruitment, retention, skills, training. The articles in this cluster are related to the subject taken in the articles from cluster 5 ; however, the authors of papers included in this group are more interested in the subject of specific instruments related to the ways of recruiting and maintaining talents in the organization. The interest is explained by the difference in approaches for personnel management depending on the skills' level of employees [46]. Personnel selection plays an important role in further companies' performance and competitiveness [47]. Various techniques can be applied in order to sustain and develop skills of employees. Nowadays it is common trend that employees select companies that provide opportunities for personal development.

Based on the keywords from each cluster and analysis of the articles from a given group, each of them was attempted to be provided with a name that could allow the identification of the dominant research perspective taken by the authors (table 1).

As the table 1 shows, the analysis of clusters from the Scopus database facilitated their combination according to different research perspectives. Thus, clusters 1, 2 and 4 present the regional perspective and contain analysis on the overall economic level. Clusters 4, 5 and 6 show organizational perspective and generally focus on the research and description of companies' context. However, cluster 3 is of a mixed nature and besides the organizational level contains employees' aspect.

Table 1. Clusters of research trends identified in the Scopus databas

\begin{tabular}{lll}
\hline No. & Name of cluster & Research Perspectives \\
\hline 1 & Educated human capital including creative class as a labour market resource & Country, Regional \\
2 & Job satisfaction and motivation of human resources & Country, Regional \\
3 & Organizational, Employee \\
4 & Determinants of productivity on the labour market & Country, Regional \\
6 & Employer branding in the context of talent management & Organizational \\
\hline
\end{tabular}




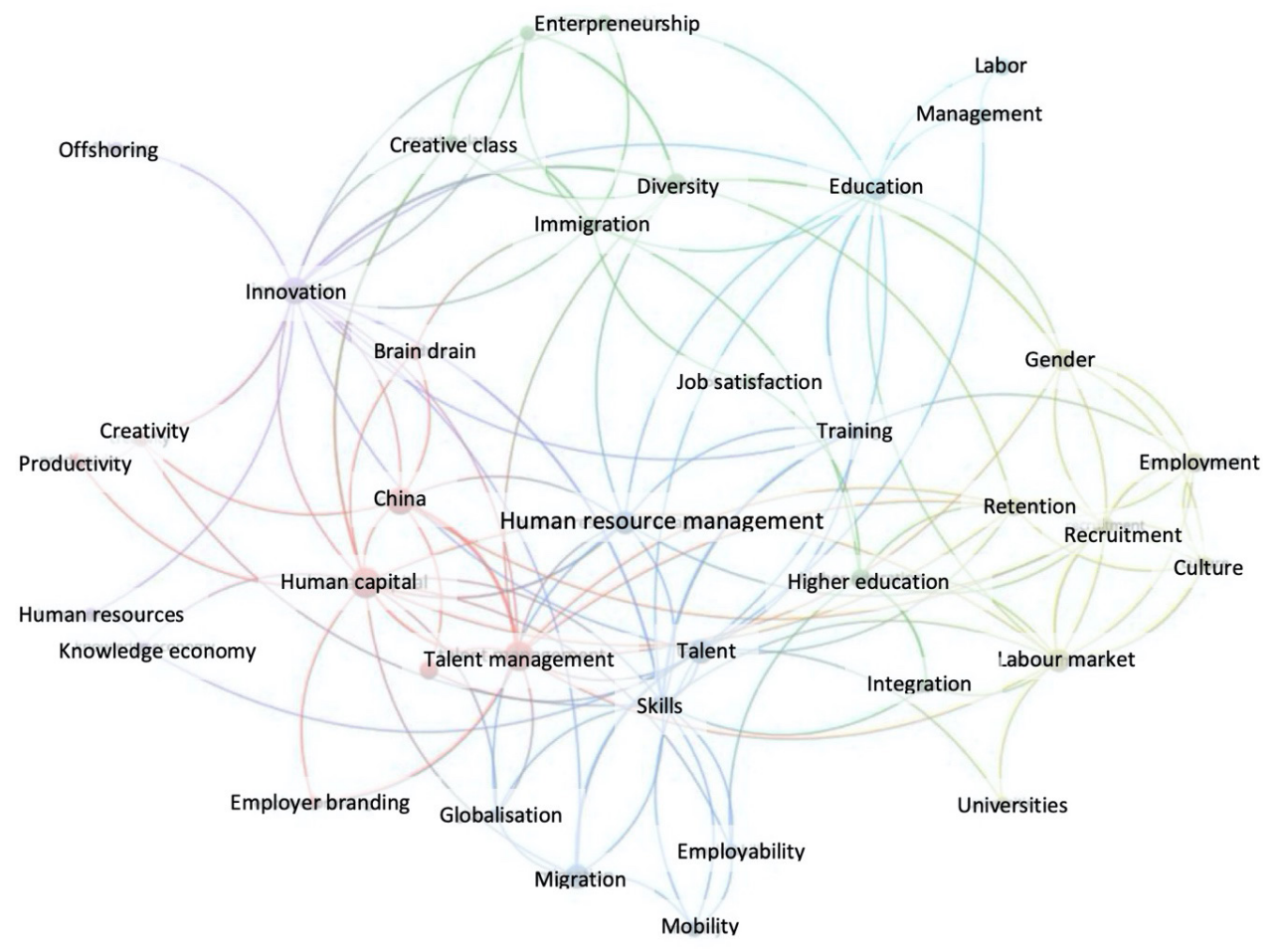

Figure 8. Map of research trends (WoS)

Cluster number one in the WoS database included eight keywords: brain drain, China, creativity, employer branding, human capital, labor market, productivity, talent management. In this cluster, one of the issues covered is the rapid development of China, that causes the need for changes in talent management. The connection between the motivation of technological innovation talents, such as wages, and technological innovation efficiency is becoming more complex [48]. China as a country with the lower costs of the labour force on the labour market is an attractive destination for international companies that seek talented but cheap employees [49]. Articles in this cluster take up the subject of creativity and productivity of talents, as well as specific ways of managing them in the organization, also with the use of the employer branding policy.

In cluster two there were eight keywords: creative class, diversity, economic development, entrepreneurship, higher education, immigration, integration, job satisfaction. This cluster indicates a relationship among creative class, labour force diversity (in connection with immigrant labour) and higher education with economic development and entrepreneurship which have also broader, not only economic effects of integration and job satisfaction. Universities that aim to attract and retain talents tend to develop their academic staff, increase the availability of research funding, and perceive these activities as an invest- ment [50].

Cluster number three included eight keywords: employability, globalization, human resource management, migration, mobility, skills, talent, training. In this cluster, the case of globalization as a background for the increased mobility of human capital is covered. Growing mobility of labour force requires modification of human resource management approach to control and stimulate flows of talents. Migration of talents is scoped from the point of view of receiving country and country of origin. Countries that attract more talents are more advanced. In classic approaches for employment, recruitment is viewed as a reactive approach when companies search for employees only when a vacancy appears, whereas the approach for sustainable talent acquisition means that companies provide a steady supply of talents to meet probable future needs [51].

In cluster four there were seven keywords: culture, employment, gender, labour market, recruitment, retention, universities. The fourth cluster includes articles dealing with the subject of relations between culture and the labour market, also in the context of possible ways of acquiring and retention of employees in the organization. Regional context, emerging from the cultural, traditional, institutional, economic, etc. factors, matters in defining talents and elaborating talent management policies [19].

Cluster number five consisted of four keywords: 
human resources, innovation, knowledge economy, offshoring, In the cluster, the issue of global changes is covered. Globalization, digitalization, the rapid development of technology and innovation requires adequate changes in human resource management [52]. The relationship between technological innovation talents, as the most effective labour force, and technological innovation efficiency is becoming more complex, that requires more effort from a company for successful and reasonable resource-management [48]. Operation in the conditions of knowledge economy demands from human resources to be flexible, make effective decisions in changing surrounding. However, the behavior of companies remains rational, and they seek for more talented, yet, lower costed employees, that contributes to the development of offshoring centers in the countries with emerging economies [49].

In the last cluster could be found three keywords: education, labor, management. The sixth cluster describes the necessity of the development of skills, abilities and knowledge of employees; motivation of talented employees via support and creation the favorable conditions for them. Among others, the following tools for development are encountered: individual development map, long-term professional career motivation, WorldSkills, mentoring, self-education and self-realization, generation of innovative ideas [52].

Taking into account keywords from each cluster, as well as analyzing the articles that were included in a given group, it was attempted to provide them with names and thus indicate the dominant research perspective taken by the authors (table 2).

According to the bibliometric analysis of the publications, indexed by $\mathrm{WoS}$ on the selected topic, 6 clusters were identified. As the table 2 shows, clusters 1, 2, 3, 4 and 5 have their focus on the regional perspective with the comprehensive investigation on the economic level. Clusters 3 and 6 are concentrated on the organizational level and cover the researches connected with the situation in enterprises.

\section{Discussion and Conclusions}

The concept of talent is widely recognized as a part of human capital and a current flow of human resource management. The literature analysis demonstrates that the definition of "talent" and its close synonyms, is viewed differently. Partially, it depends on the country of analysis, the sphere of economic activity, features of the labour force under investigation. Generally, the researchers conclude that to the key category "talent" can belong to those individuals who have high qualifications or specific skills in professions, that are hard to be achieved or repeated by other labour force. There are two main streams of the analysis of talents in literature: the study of the demands from the business and regional perspectives. However, the literature analysis shows that those two

Table 2. Clusters of research trends identified in the os database

\begin{tabular}{|c|c|c|}
\hline No. & Name of cluster & Research Perspectives \\
\hline 1 & Determinants of productivity on the labour market - the case study of China & $\begin{array}{l}\text { Country } \\
\text { Regional }\end{array}$ \\
\hline 2 & Educated human capital including creative class as a labour market resource & $\begin{array}{l}\text { Country } \\
\text { Regional }\end{array}$ \\
\hline 3 & The impact of globalization and internationalization on human resource management & $\begin{array}{c}\text { Country } \\
\text { Regional } \\
\text { Organizational }\end{array}$ \\
\hline 4 & Culture and gaining and keeping talents & $\begin{array}{l}\text { Country } \\
\text { Regional }\end{array}$ \\
\hline 5 & The impact of innovation and technology on talent management & $\begin{array}{c}\text { Country } \\
\text { Regional } \\
\text { Organizational }\end{array}$ \\
\hline 6 & Ways of att acting talents in organizations & Organizational \\
\hline
\end{tabular}


streams complement each other because besides the financial motivation talents require appropriate surrounding.

Regardless of the popularity of the talent management topic, the bibliometric analysis approach is underused, and only a few publications are available. The most advanced studies in terms of talent management using bibliometric and content analysis were conducted by Eva Gallardo-Gallardo et al. [53]. They present theoretical frameworks of talent management and classify research approaches. While, in this publication, the authors identify clusters concerning the main research trends of the concept of "talent" in the labour management perspective.

The results of the bibliometric analysis show that the literature related to talent in terms of labour resources is increasing in various scientific fields.

The identified clusters prove that studies are made on the macro, organizational and individual levels. The main researched areas related to talent in the labour management perspective consider migration of highly skilled workers, the importance of education of human capital, job satisfaction and motivation of human resources, determinants of productivity on the labour market, employer branding in the context of talent management, ways of attracting of talents in organizations, the impact of globalization and internationalization on human resource management, the influence of innovation and technology on talent management. In both Scopus and WoS, six clusters were identified. Concerning Scopus, three of the clusters covered the regional perspective; two clusters were dedicated purely to the organizational perspective; one was of a mixed nature and was dedicated both to organizational and employees' aspects. Regarding WoS, four clusters are exclusively focused on the regional perspective; one cluster is purely dedicated to the organizational perspective; one is of a mixed nature and contains both regional and organizational perspectives. Thus, in both of the investigated databases, the focus is on the regional and organizational perspectives; however, one of the clusters in Scopus amplifies the employees' context as well.

The principal limitations of the research are based on the fact that the analysis was mainly conducted on the basis of Scopus and WoS databases, that dispose of a limited number of publications. However, the publications in those databases reflect the current state of knowledge; consequently, the outcomes of this paper can be scalable. As for the topics of further research, the clusters identified in the current paper can be used. Additionally, multitudinous and diversity of identified clusters within the current study shows the necessity of the qualitative analysis that will explain in details not only keywords but also key concepts applied, research methods and results.

\section{Funding}

This research did not receive any specific grant from funding agencies in the public, commercial, or not-for-profit sectors.

\section{References}

[1] S. E. Khilji, I. Tarique, R. S. Schuler, "Incorporating the macro view in global talent management". Human Resource Management Review, 25/3, September 01, 2015, pp. 236248; doi: 10.1016/j.hrmr.2015.04.001

[2] S. Keller and M. Meaney, "Attracting and retaining the right talent”. 2017, Available: https:/www.mckinsey.com/ business-functions/organization/our-insights/attractingand-retaining-the-right-talent (accessed: 15.10.2018).

[3] M. Painter-Morland, S. Kirk, G. Deslandes, and C. Tansley, "Talent Management: The Good, the Bad, and the Possible”. Eur. Manag. Rev., 16, 2019, pp. 135- 146. https://doi.org/10.1111/emre.12171.

[4] J. Uribe-Toril, J. Ruiz-Real, and J. de Pablo Valenciano, "Gentrification as an Emerging Source of Environmental Research, Sustainability, 10/12, 2018, 4847; doi: 10.3390/su10124847.

[5] M. Cowling, N. Lee, "How entrepreneurship, culture and universities influence the geographical distribution of UK talent and city growth". Journal of Management Development, $36 / 2, \quad$ pp. 178-195; doi: 10.1108/JMD-03-2016-0043

[6] S. A. Azizan, "Strengthening Malaysia's Scientific and Technological Development through Human Capital Development”. Procedia Soc Behav Sci, 91, 2013, pp. 648653. doi: 10.1016/j.sbspro.2013.08.465.

[7] T. Schultz, "Investment in human capital". Am. Econ. Rev. 51/2, 1961, pp. 1-17.

[8] K. Jerzak, "The Essence of Human Capital in a Building Company - Selected Aspects". Procedia Eng., 122, 2015, pp. 95 - 103. doi: 10.1016/j.proeng.2015.10.012.

[9] S. Beechler and I. C. Woodward, "The global "war for talent”". J. Int. Manag., 15, 2009, pp. 273-285. doi: 10.1016/j.intman.2009.01.002

[10] U. Pauli, A. Pocztowski, "Talent Management in SMEs: An Exploratory Study of Polish Companies". Entrepreneurial Business and Economics Review, 7/4, 2019, pp. 199-218; https://doi.org/10.15678/EBER.2019.070412.

[11] S. Estrin, T. Mickiewicz, and U. Stephan, "Human capital in social and commercial entrepreneurship". J. Bus. Ventur. 31/4, 2016, pp. 449 - 467. doi: 10.1016/j.jbusvent.2016.05.003.

[12] J. Kiuru and T. Inkinen, "Predicting innovative growth and demand with proximate human capital: A case study of the Helsinki metropolitan area”. Cities, 64, 2017, pp. 9-17. doi: 10.1016/j.cities.2017.01.005.

[13] G. Sefer, A. Sudi, H.G. Gümüş, and Z. Kurban, "An Application in Human Resources Management for Meeting Differentiation and Innovativeness Requirements of Business: Talent Management". Procedia Soc Behav Sci, pp. 99, 2013, pp. 794 - 808. doi: 10.1016/j.sbspro.2013.10.551.

[14] A. Pinnington et al., "Early Organizational Diffusion of Con 
temporary Policies: Narratives of Sustainability and Talent Management". Procedia Soc Behav Sci, 213, 2015, pp. 807 - 811, doi: 10.1016/j.sbspro.2015.11.480.

[15] ILO, "International Standard Classification of Occupations: ISCO-08”. International Labour Organization. Geneva, 2012, Available: https:/www.ilo.org/wcmsp5/groups/public/--dgreports/---dcomm/---publ/documents/publication/wcms_ 172572.pdf (accessed: 20.05.2019).

[16] T. Strenze, "Allocation of talent in society and its effect on economic development”. Intelligence, 41, 2013, pp. 193202. doi: 10.1016/j.intell.2013.03.002.

[17] C. Zheng, C. Soosay, and P. Hyland, "Manufacturing to Asia: who will win the emerging battle for talent between Dragons and Tigers?".J Manuf Technol Mana., 19/1, 2007, pp. 52-72, doi: 10.1108/17410380810843453

[18] E. Michaels, H. Handfield-Jones, and B. Axelrod. "The War for Talent". Boston, Mass: Harvard Business Press. 2001.

[19] F. L. Cooke, D. S. Saini, and J. Wang, "Talent management in China and India: A comparison of management perceptions and human resource practices". J. World Bus., 49, 2014, pp. 225-235. doi: 10.1016/j.jwb.2013.11.006.

[20] B. Crane and C.J. Hartwell, "Global talent management: A life cycle view of the interaction between human and social capital”. J. World Bus., 54/2, 2018, 8292. doi: 10.1016/j.jwb.2018.11.002.

[21] T. Berger and C. Frey, "Structural Transformation in the OECD: Digitalisation, Deindustrialisation and the Future of Work", OECD Social, Employment and Migration Working Papers, 193, 2016, OECD Publishing, Paris. doi: 10.1787/5jlr068802f7-en

[22] K.R. Dotzel, "Do natural amenities influence undergraduate student migration decisions?". Ann. Regional Sci., 59/3, 2017, pp. 677-705.

[23] W. Ha, J. Yi, J. Zhang, "Brain drain, brain gain, and economic growth in China", China Economic Review, 38/01, 2016, pp. 322-337; 10.1016/j.chieco.2015.02.005.

[24] J. Gibson and D. Mckenzie, "Eight questions about brain drain”. J. Econ. Perspect., 25/3, 2011, pp. 107-128.

[25] L. Espinoza Pedraza, "Brain Drain: Social and Political Consequences in Developing Countries". Revista Grafía, 10(2), 2013, pp. 29-48. doi: 10.26564/16926250.492

[26] I. Tarique and R.S. Schule, "Global talent management: Literature review, integrative framework, and suggestions for further research”. J. World Bus, 45/2, 2010, pp. 122-133. doi: 10.1016/j.jwb.2009.09.019.

[27] S. Silvanto, J. Ryan, Y. McNulty, "An empirical study of nation branding for attracting internationally mobile skilled professionals". Career Development International, Vol. 20 No. 3, 2015, pp. 238-258. doi: 0.1108/CDI-08-2014-0105

[28] A. Mihi-Ramirez and V. Kumpikaite, "Economics reason of migration from point of view of students", Procedia - Social and Behavioral Sciences 109, 2014, pp. 522 - 526.

[29] Y. Khwaja, "Should I stay or should I go? Migration under uncertainty: a real options approach". Economics and Finance Section, School of Social Sciences, Brunel University; Public Policy Discussion Papers, No. 02-10, 2002.

[30] M. Korpi and W.A.V. Clark, "Internal migration and human capital theory: To what extent is it selective?". Economics Letters, 136, 2015, pp. 31-34. doi: 10.1016/j.econlet.2015.08.016.

[31] D.G. Papademetriou and M. Sumption, "Attracting and selecting from the global talent pool - policy challenges". Migration Policy Institute. 2013. Available: https:/www.migrationpolicy.org/research/attracting-andselecting-global-talent-pool--policy-challenges (accessed on 20.10.2018)

[32] M. Álvarez-Melgarejo and M. Torres-Barreto, "Can resources act as capabilities foundations? A bibliometric analysis”, Revista UIS Ingenierías, 17/2, 2018, pp. 185-200. doi: 10.18273/revuin.v17n2-2018017.

[33] M. Gaviria-Marin, J.M. Merigó, and H. Baier-Fuentes, "Knowledge management: A global examination based on bibliometric analysis". Technol Forecast Soc Change, 140, 2019, pp. 194-220. doi: 10.1016/j.techfore.2018.07.006.

[34] A. E. Gudanowska, "Modern research trends within technology management in the light of selected publications". Procedia Eng. 182, 2017, 250. DOI: 10.21008/j.2083-4950.2017.7.5.4.

[35] E. Cichowicz and E. Rollnik-Sadowska, "Inclusive Growth in CEE Countries as a Determinant of Sustainable Development”. Sustainability, 10, 2018: 3973.

[36] J. Siderska and K.S. Jadaan, "Cloud manufacturing: a service-oriented manufacturing paradigm”. Eng. Manag. Prod. Serv., 10, 2018, pp. 46-55. doi: 10.1515/emj-2018-0002.

[37] E. Glińska and D. Siemieniako, "Binge drinking in relation to services - bibliometric analysis of scientific re search directions”. Eng. Manag. Prod. Serv., 10/1, 2018, pp. 45-54. doi: 10.1515/emj-2018-0004.

[38] N.J. van Eck and L. Waltman, "Visualizing bibliometric net works". In Y. Ding, R. Rousseau, \& D. Wolfram (Eds.), Measuring scholarly impact: Methods and practice, 2014, pp. 285-320. doi: 10.1007/978-3-319-10377-8_13

[39] J. Aboites and C. Díaz, "Inventors' mobility in Mexico in the context of globalization”. Scientometrics, 115/3, 2018, pp. 1443-1461. doi: 10.1007/s11192-018-2645-6.

[40] L. Zong and Y. Lu, "Reconceptualization of "brain drain". Int. J. Chin. Educ. 6/2, 2017, pp. 288-314. doi: 10.1163/22125868-12340084.

[41] H. Qian, "Talent, creativity and regional economic performance: the case of China”. Ann Regional Sci, 45/1, 2010, pp. 133-156. doi 10.1007/s00168-008-0282-3.

[42] Y. Zhou, Y. Guo, Y. Liu, "High-level talent flow and its influence on regional unbalanced development in China". Applied Geography, 91, 2018, pp. 89-98. doi: 10.1016/j.apgeog.2017.12.023

[43] J. Piirt, Entry. Talent and creativity. In M. Runco and S. Pritzker (Eds.), Encyclopedia of Creativity, 2nd Ed. vol. 2, 2011, pp. 427-434. San Diego, CA: Academic Press.

[44] Korobaničová I. and Kovácová N., "Human Capital Investment: Practices and Measurement in Slovak Enterprises”. Int J Ind Eng Manag. 9/3, 2018, pp. 139-146, doi: 10.24867/IJIEM-2018-3-139.

[45] N. Gourova and E. Gourova, "Attracting talents". ACM International Conference Proceeding Series, 2018, doi: 10.1145/3158491.3158497.

[46] W. Kwon, "Human Capital Risk and Talent Management Issues in the Insurance Market: Public Policy, Industry and Collegiate Education Perspectives". The Geneva Papers on Risk and Insurance - Issues and Practice 39/1, 2014, pp. 173-196. doi: 10.1057/gpp.2013.11.

[47] R. I. Vosloban, "The Influence of the Employee's Performance on the Company's Growth - A Manageri al Perspective". Procedia Economics and Finance, Volume 3, 2012, pp. 660-665. doi: 10.1016/S2212-5671(12)00211-0

[48] X. Dai, J. Wu, and L. Yan, "A Spatial Evolutionary Study of Technological Innovation Talents' Sticky Wages and Technological Innovation Efficiency Based on the Perspective of Sustainable Development". Sustainability 10/11, 2018, 4201. doi: 10.3390/su10114201.

[49] N. Majid, "The great employment transformation in China". Employment Working Paper, No. 195, ILO, 2015.

[50] S. Neri and S. Wilkins, "Talent management in transnational higher education: strategies for managing academic staff at international branch campuses". J. High. Educ. Policy Manag. 41/1, 2018, pp. 52-69. doi: 
10.1080/1360080X.2018.1522713.

[51] M. Mohapatra and P. Sahu, "Building a Sustainable Talent Acquisition Model in a Dynamic Business Environment". International Journal of Human Capital and Information Technology Professionals, 9/3, 2018, pp. 42-52. doi: 10.4018/IJHCITP.2018070103.

[52] R.R. Iscandarov, T.G . Mansurova, and N.V. Rudneva, "Talent management as a method of development of the human capital of the company". Revista San Gregorio is., 25, 2018, pp. 105-110.

[53] E. Gallardo-Gallardo, S. Nijs, N. Driesc, and P. Gallo, "Towards an understanding of talent management as a phenomenon-driven field using bibliometric and content analysis". Hum. Resour. Manag. Rev., 25/3, 2015, pp. 264279. doi: 10.1016/j.hrmr.2015.04.003. 